\title{
A dichloromethane fraction of Triticum aestivum sprouts reduces allergic immune response through inhibiting Th2 differentiation in ovalbumin-immunized mice
}

\author{
HYEON-HUI KI ${ }^{1,2}$, SUNG-WOO HWANG ${ }^{1}$, JI-HYUN LEE ${ }^{2}$, YOUNG-HO KIM ${ }^{3}$, \\ DAE-KI KIM $^{2}$ and YOUNG-MI LEE ${ }^{1}$ \\ ${ }^{1}$ Department of Oriental Pharmacy, College of Pharmacy and Wonkwang-Oriental Medicines Research Institute, \\ Wonkwang University, Iksan, Jeonbuk 54538; ${ }^{2}$ Department of Immunology and Institute for Medical Sciences, \\ Medical School, Chonbuk National University, Jeonju, Jeonbuk 54907; ${ }^{3}$ College of Pharmacy, \\ Chungnam National University, Daejeon 34134, Republic of Korea
}

Received March 21, 2017; Accepted July 7, 2017

DOI: $10.3892 / \mathrm{mmr} .2017 .7020$

\begin{abstract}
Triticum aestivum sprouts are small shoots that germinate from seeds and are consumed as a dietary supplement. The present study aimed to determine whether a dichloromethane fraction isolated from Triticum aestivum sprouts (TDF) suppressed the allergic immune response in ovalbumin (OVA)-sensitized mice. In vivo experiments were performed by administering TDF or vehicle to mice during the sensitization and this was immediately followed by an intradermal injection of OVA into the ears. Splenocytes isolated from OVA-sensitized mice were pre-treated with TDF and re-challenged with OVA for ex vivo evaluation. Results demonstrated that TDF suppressed the inflammatory response in ear tissues and levels of total immunoglobulin ( $\mathrm{Ig}) \mathrm{E}$ and OVA-specific IgE in serum. TDF inhibited the production of interleukin (IL)-4 and expression of GATA-binding protein-3 (GATA-3) transcription factor which regulates the differentiation of naïve $\mathrm{T}$ helper (Th) cells into Th2 cells in OVA-stimulated splenocytes. TDF inhibited Th1-associated cytokine interferon $-\gamma$ and IL-12 production and downregulated the expression of Th1 specific transcription factor T-box 21 in OVA-stimulated splenocytes. Overall, these results indicated that TDF attenuates OVA-induced allergic immune response
\end{abstract}

Correspondence to: Professor Young-Mi Lee, Department of Oriental Pharmacy, College of Pharmacy and Wonkwang-Oriental Medicines Research Institute, Wonkwang University, 460 Iksan-daero, Iksan, Jeonbuk 54538, Republic of Korea

E-mail: ymlee@wonkwang.ac.kr

Professor Dae-Ki Kim, Department of Immunology and Institute for Medical Sciences, Medical School, Chonbuk National University, 567 Baekje-daero, Deokjin-gu, Jeonju, Jeonbuk 54907, Republic of Korea

E-mail:daekim@jbnu.ac.kr

Key words: Triticum aestivum sprouts, anti-allergic activity, ovalbumin, immunoglobulin E, T helper cells by suppressing the production of Th2 specific cytokine IL-4, through inhibiting transcription factor GATA-3, and suggests that TDF may exhibit the potential to regulate the immune response in allergic diseases.

\section{Introduction}

Allergies are hypersensitivity reactions initiated in response to various environmental allergens. During sensitization to allergens through skin, and the respiratory and digestive tracts, $\mathrm{B}$ cells differentiate into immunoglobulin-producing cells and produce allergen-specific IgE, which binds to high-affinity receptor (FceRI) on surfaces of mast cells in the connective or mucosal tissues (1). Subsequent exposure to the allergen activates mast cells through the cross-linking of FceRI-IgE complexes, and activated mast cells then release amines with inflammatory vascular effects (e.g. histamine), leukotrienes derived from arachidonic acid, heparin, proteases, cytokines and chemokines. These factors promote allergic immune response by regulating the differentiations and activations of various immune cells and induce lymphocyte infiltration to the inflamed site (2). In addition, allergen-specific CD4 ${ }^{+}$ Th2 cells are known to play important roles in the initiation and maintenance of allergic response (3). Cytokines (e.g. IL-4, IL-5, and IL-13) secreted by Th2 cells induce B cells to produce $\operatorname{IgE}$ and activate immune cells, including mast cells, basophils and eosinophils. On a macro scale, these responses cause mucus hypersecretion, epithelium fibrosis and are even associated with tissues damage (4).

Many medications used to treat allergic conditions, including antihistamines and corticosteroids, can cause side-effects. For example, long-term corticosteroid therapy may cause Cushing's syndrome, osteoporosis and adrenal insufficiency (5-7). Therefore, new therapeutic agents for the allergic diseases are today's need. Numerous authors have suggested that plant-derived drugs are intrinsically safer than synthetic drugs $(8,9)$.

Triticum aestivum sprouts germinate from seed and contain large amounts of chlorophyll, minerals, enzymes, 
and other functional entities (10). Eosinophil accumulation and activation have been shown to play an important role in the pathogenesis of allergic inflammation and asthma $(11,12)$. Studies have reported that in thalassemic patients with eosinophilia, Triticum aestivum sprouts reduced in the numbers of eosinophils in blood (13). We previously showed that a dichloromethane fraction isolated from Triticum aestivum sprouts (TDF) contains large amounts of sterols (e.g. $\beta$-sitosterol) and polyunsaturated fatty acids (e.g. $\alpha$-linolenic acid) and glycolipids (14). Other studies have reported that $\beta$-sitosterol has potential anti-allergic effects $(15,16)$, and increasing evidence indicates polyunsaturated fatty acids alleviate allergic diseases $(17,18)$.

However, the effects of TDF on allergic immune response have not been elucidated. In the present study, we examined the anti-allergic activity and mechanism of action of TDF in an OVA-sensitized mouse model.

\section{Materials and methods}

Extraction and isolation of plant material. Triticum aestivum were supplied by the Korean National Institute of Crop Science and were germinated on sterile organic feat moss (at $20 \pm 2^{\circ} \mathrm{C}$ ). The dichloromethane fraction was obtained from from Triticum aestivum sprouts (TDF) as previously described (14). Briefly, Triticum aestivum sprouts were cultivated for two weeks after germination, harvested, lyophilized and crushed to obtain a powder with a predetermined particle size. Frozen powder $(30 \mathrm{~g})$ was then extracted with methanol. And the extract was dissolved in $800 \mathrm{ml}$ of water and partitioned sequentially with hexane, dichloromethane $\left(\mathrm{CH}_{2} \mathrm{Cl}_{2}\right)$, ethyl acetate (EtOAc) and n-butanol. TDF was filtered through Whatman filter paper (grade no. 1, diameter: $15 \mathrm{~cm}$ ) and concentrated under reduced pressure using a rotary evaporator (N-1000; EYELA, Tokyo, Japan).

In vivo experiments. Female BALB/c mice (6 weeks old) were purchased from Samtako (Osan, Korea), and acclimated in a pathogen-free facility for 2 weeks prior to experiments. Animals were kept in an air-conditioned room $\left(22 \pm 2^{\circ} \mathrm{C}\right.$, $55 \pm 10 \% \mathrm{RH}$ ) and fed 5L79 rodent diet (Orient Bio, Seongnam, Korea) throughout the experimental period. The ovalbumin (OVA)-sensitized mouse model of this study was previously described by Park et al (19). After acclimation to the facility's environment, mice were divided into five groups $(\mathrm{n}=5$ each): Group 1; $1 \%$ carboxymethyl cellulose (vehicle), group 2; OVA sensitization + vehicle, group 3; OVA sensitization + TDF $100 \mathrm{mg} / \mathrm{kg}$, group 4; OVA sensitization + TDF $200 \mathrm{mg} / \mathrm{kg}$, group 5; OVA sensitization + dexamethasone $0.5 \mathrm{mg} / \mathrm{kg}$. On the first day, all mice were intraperitoneally (i.p.) sensitized with $20 \mu \mathrm{g}$ OVA (grade V; Sigma-Aldrich, St. Louis, MO, USA) and $1 \mathrm{mg}$ of aluminum hydroxide (Imject ${ }^{\circledR}$ A lum; Thermo Scientific, Cramlington, UK) dissolved in $100 \mu \mathrm{l}$ of phosphate-buffered saline (PBS, pH 7.4); except mice in the group 1. Two weeks later, mice were administered a second i.p. injection of OVA and alum. To investigate in vivo effect of TDF on allergic immune response, OVA-sensitized mice were orally administered TDF or dexamethasone (p.o.) once daily for 13 days following the second OVA injection. All animal experiments were conducted after obtaining approval from the Institutional Animal Care and Use Committee (IACUC) at Chonbuk National University Laboratory Animal Center.

Ear swelling test. The ear swelling test was performed to analyze the allergic response with reference to the previous studies $(20,21)$. Mice were injected subcutaneously with $20 \mu \mathrm{l}$ of $0.1 \%(\mathrm{~m} / \mathrm{v})$ OVA solution dissolved in PBS into ear skin after the 13 days treatment period. Ear thicknesses of mice were measured using a thickness gauge (Mitutoyo, Tokyo, Japan) at 6 and $24 \mathrm{~h}$ after OVA injection.

Histological examination. Animals were sacrificed by cervical dislocation method under diethyl ether anesthesia. Ear tissues of animals were harvested at $24 \mathrm{~h}$ after final OVA challenge for histological examination. Tissues were fixed with $10 \%$ formalin and then embedded in paraffin. Tissue sections (4 $\mu \mathrm{m})$ were obtained using a microtome for hematoxyin and eosin (H\&E) staining, according to the previous report (22), and stained sections were examined under an optical microscope (CX21; Olympus, Tokyo, Japan).

Serum analysis of immunoglobulins. After sacrifice, blood was collected from abdominal inferior vena cava and centrifuged at $3,000 \mathrm{rpm}$ for $10 \mathrm{~min}$. Serum levels of total immunoglobulin $(\mathrm{Ig}) \mathrm{E}$ and $\mathrm{IgG1}$ were evaluated using commercial ELISA kits (BD Biosciences, San Jose, CA, USA), and the serum levels of OVA-specific IgE and OVA-specific IgG1 were measured using a detection kit obtained from Shibayagi (Gunma, Japan).

Preparation of splenocytes. Spleens were removed from OVA-sensitized mice and filtered using $100 \mu \mathrm{m}$ cell strainers. Single-cell suspensions and Histopaque ${ }^{\circledR} 1119$ (Sigma-Aldrich) were mixed and centrifuged at 1,600 rpm for $30 \mathrm{~min}$ to remove erythrocytes. The cell pellets so obtained were washed twice with PBS, and cultured in RPMI-1640 (HyClone Laboratories, Logan, UT, USA) supplemented with heat-inactivated $10 \%$ fetal bovine serum (FBS), $100 \mathrm{U} / \mathrm{ml}$ of penicillin and $100 \mu \mathrm{g} / \mathrm{ml}$ of streptomycin at $37^{\circ} \mathrm{C}$ in a humidified $5 \% \mathrm{CO}_{2}$ incubator. Splenocytes were used for experiment after stabilization.

Reverse transcription polymerase chain reaction (RT-PCR) and quantitative $R T-P C R$ ( $q R T-P C R)$. Splenocytes were treated with OVA and various concentrations of TDF for $24 \mathrm{~h}$, and total RNA was extracted from splenocytes with TRIzol reagent (Invitrogen, Carlsbad, CA, USA). cDNA synthesis were performed using the SuperScript ${ }^{\mathrm{TM}}$ III First Synthesis system for RT-PCR kit (Invitrogen) and $1 \mu \mathrm{g}$ of total RNA. Template of cDNA (50 ng) was amplified using $1 \mathrm{X}$ reaction buffer, $10 \mathrm{mM}$ dNTP mixture, 5 units of Taq polymerase (GeNet Bio, Seoul, Korea) and RT-PCR primers. Amplified gene products were loaded into $1.5 \%$ agarose gel containing ethidium bromide, all gene expressions were normalized vs. GAPDH of each sample. qRT-PCR method was previously described (23). Primer sequences are summarized in Table I.

Th1/Th2 cytokine assay. After preparation, splenocytes were incubated with various concentration of TDF in presence or absence of OVA $(100 \mu \mathrm{g} / \mathrm{ml})$ for $48 \mathrm{~h}$. Th1 (IFN- $\gamma$, IL-12) and Th2 (IL-4, IL-5, IL-13) cytokines in cell culture supernatants 
Table I. Primer sequences and product size used for RT-PCR and qRT-PCR.

\begin{tabular}{|c|c|c|c|}
\hline Gene & Forward primer $\left(5^{\prime}-3^{\prime}\right)$ & Reverse primer (5'-3') & Size (bp) \\
\hline IFN- $\gamma$ & СТTCTTCAGCAACAGCAAGGCGAAAA & CCCCCAGATACAACCCCGCAATCA & 456 \\
\hline IL-12 & AACCTCACCTGTGACACGCC & CAAGTCCATGTTTCTTTGCACC & 309 \\
\hline IL-4 & GAGATCATCGGCATTTTGAAC & CTTGGACTCATTCATGGTGCA & 267 \\
\hline IL-5 & GAAAGAGACCTTGACACAGCTG & GAACTCTTGCAGGTAATCCAGG & 277 \\
\hline IL-13 & ATGAGTCTGCAGTATCCCG & CCGTGGCAGACAGGAGTGTT & 194 \\
\hline GAPDH (RT-PCR) & GCCAAGGTCATCCATGACAAC & GTCCACCACCCTGTTGCTGTA & 498 \\
\hline T-bet & ACTTTGAGTCCATGTACGCATCT & AGGATACTGGTTGGATAGAAGAGGT & 113 \\
\hline GATA-3 & TACCACCTATCCGCCCTATGT & ACACACTCCCTGCCTTCTGT & 138 \\
\hline GAPDH (qRT-PCR) & CATGGCCTTCCGTGTTC & CCTGGTCCTCAGTGTAGC & 152 \\
\hline
\end{tabular}

IFN- $\gamma$, interferon- $\gamma$; IL, interleukin; T-bet, T-box 21; GATA-3, GATA binding protein-3; GAPDH, glyceraldehyde 3-phosphate dehydrogenase

A

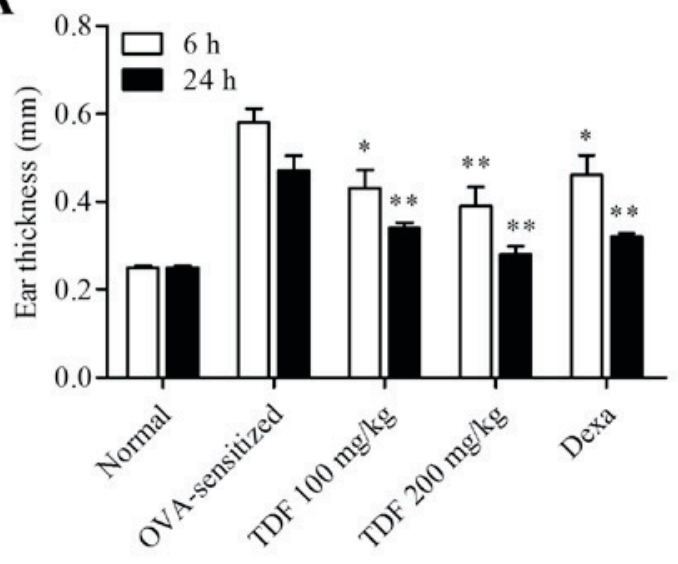

B

Normal

OVA -sensitized TDF
$100 \mathrm{mg} / \mathrm{kg}$ TDF $200 \mathrm{mg} / \mathrm{kg}$
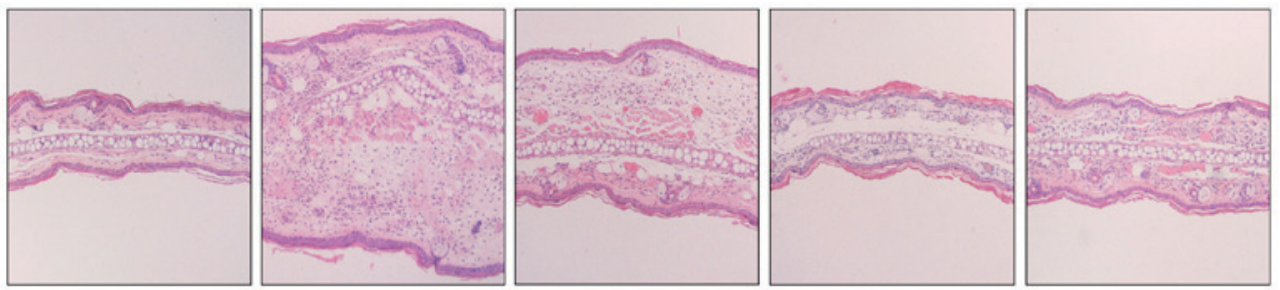

Figure 1. The effect of TDF on allergic skin response in OVA-sensitized mice. (A) Ear swelling response at 6 and $24 \mathrm{~h}$ after challenge were measured using a thickness gage. (B) Ear tissues were removed from OVA-sensitized mice at $24 \mathrm{~h}$ after $20 \mu 1$ of $0.1 \%$ OVA challenge. Samples were fixed with $10 \%$ formalin and embedded in paraffin. Histology of ear skin was examined by H\&E staining. Original magnification: $x 400$. Results are presented as the means \pm SEMs of five mice per group. ${ }^{*} \mathrm{P}<0.05$ and ${ }^{* *} \mathrm{P}<0.01$ vs. OVA-sensitized group.

were measured using the following ELISA kits: mouse IFN- $\gamma$, IL-12 and IL-4 kits were purchased from BioLegend (San Diego, CA, USA) and mouse IL-5 and IL-13 kits from eBioscience (San Diego, CA, USA).

Statistical analysis. Results are presented as means \pm SEMs. The Student's t-test was carried out to verify the difference between the control and experimental groups in GraphPad Prism software (version 5.0). Statistical significance was accepted for $\mathrm{p}$-values $<0.05$.

\section{Results}

Effect of TDF on allergic skin response in OVA-sensitized mice. Allergic inflammation can be elicited on sensitized subjects when exposure to a specific allergen (24). To investigate the inhibitory effect of TDF on cutaneous allergic response, mice were sensitized with OVA and administered TDF for 13 days, and then challenged with an s.c. injection of OVA into ears. Swelling responses were quantified by measuring ear thicknesses. As shown in Fig. 1A, ear thickness 
A

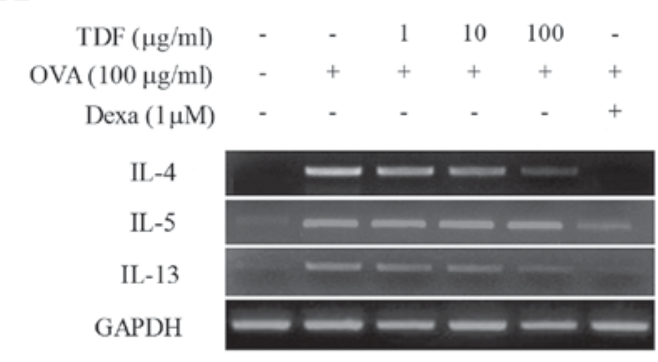

C

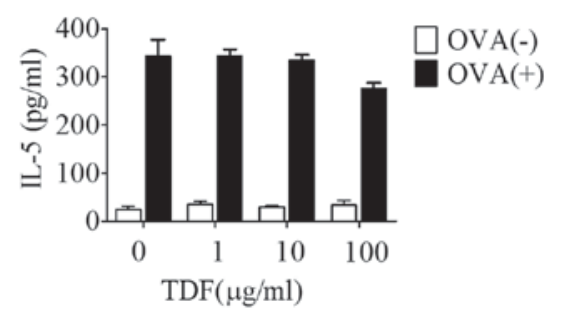

B

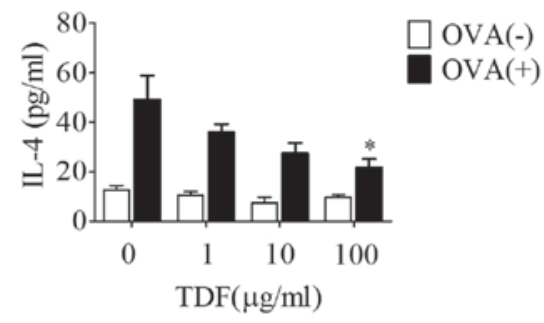

D

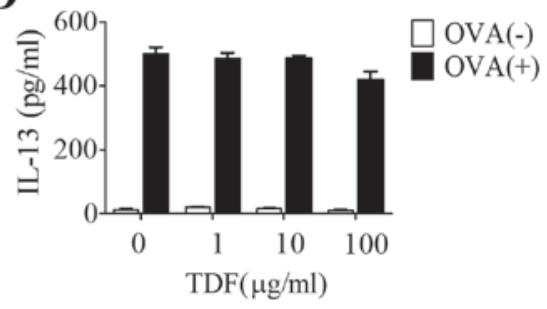

Figure 2. The effect of TDF on Th2 cytokine production in splenocyte culture. The impact of TDF on the Th2 subset was analyzed in splenocytes isolated from OVA-sensitized mice. Splenocytes were incubated with the indicated concentrations of TDF $(1,10,100 \mu \mathrm{g} / \mathrm{ml})$ in the absence or presence of $100 \mu \mathrm{g} / \mathrm{ml} \mathrm{OVA}$. (A) The mRNA expressions of Th2 response genes (IL-4, IL-5, IL-13) were assayed by RT-PCR. GAPDH was used as an internal control. Secretions of Th2 response genes (B) IL-4, (C) IL-5 and (D) IL-13 into cell supernatants was measured by ELISA. Results are presented as the means \pm SEMs of indipendent three experiments. ${ }^{*} \mathrm{P}<0.05$ vs. control.

Table II. The level of total IgE and IgG1 in serum of TDF treated OVA-sensitized mice.

\begin{tabular}{lcc}
\hline Group & $\begin{array}{c}\text { Total } \\
\operatorname{IgE}(\mu \mathrm{g} / \mathrm{ml})\end{array}$ & $\begin{array}{c}\text { Total } \\
\operatorname{IgG} 1(\mu \mathrm{g} / \mathrm{ml})\end{array}$ \\
\hline Normal & $0.90 \pm 0.44(15)$ & $847.18 \pm 181.42(35)$ \\
OVA-sensitized & $6.02 \pm 1.03(100)$ & $2389.45 \pm 206.82(100)$ \\
TDF 100 $\mathrm{mg} / \mathrm{kg}$ & $4.30 \pm 1.28(71)^{\mathrm{a}}$ & $2374.91 \pm 60.66(99)$ \\
TDF 200 $\mathrm{mg} / \mathrm{kg}$ & $3.98 \pm 0.98(66)^{\mathrm{a}}$ & $2316.73 \pm 156.32(97)$ \\
Dexa & $4.12 \pm 1.28(68)^{\mathrm{a}}$ & $1594.45 \pm 222.29(67)^{\mathrm{b}}$ \\
\hline
\end{tabular}

Data are shown as mean \pm SEMs. ${ }^{\text {a }}<0.05$ and ${ }^{b} \mathrm{P}<0.01$ vs. OVA-sensitized group.

increases were significant compared to normal group at 6 and $24 \mathrm{~h}$ post-challenge. And TDF reduced these increases.

Histological analyses of ear tissues revealed marked increases in inflammatory cell infiltration into ear skin tissues after challenge in OVA-sensitized group. But these inflammatory cells infiltrations were inhibited dose-dependently by TDF (Fig. 1B). These results demonstrated that administration of TDF contributes to improving the allergic inflammatory response.

Effect of TDF on levels of serum immunoglobulins in OVA-sensitized mice. IgE production is considered the hallmark of allergic diseases, and thus, we investigated whether TDF can regulate the serum levels of immunoglobulins in OVA-sensitized mice. It has been reported that IL-4 secreted by $\mathrm{Th} 2$ cells promotes the productions of $\mathrm{IgE}$ and $\mathrm{IgG} 4$ in human and of IgE and IgG1 in mice (25). We found significant
Table III. The level of OVA-specific IgE and IgG1 in serum of TDF treated OVA-sensitized mice.

\begin{tabular}{lcc}
\hline Group & $\begin{array}{c}\text { OVA-specific } \\
\operatorname{IgE}(\mathrm{U} / \mathrm{ml})\end{array}$ & $\begin{array}{c}\text { OVA-specific } \\
\text { IgG1(U/ml) }\end{array}$ \\
\hline Normal & $\mathrm{ND}$ & $\mathrm{ND}$ \\
OVA-sensitized & $105.74 \pm 14.68(100)$ & $4741.24 \pm 1185.42(100)$ \\
TDF 100 mg/kg & $71.58 \pm 10.43(68)^{\mathrm{a}}$ & $4721.40 \pm 634.74(100)$ \\
TDF 200 mg/kg & $57.84 \pm 5.35(55)^{\mathrm{b}}$ & $4692.22 \pm 892.12(99)$ \\
Dexa & $63.48 \pm 10.22(60)^{\mathrm{a}}$ & $3432.45 \pm 793.27(72)^{\mathrm{a}}$ \\
\hline
\end{tabular}

Data are shown as mean \pm SEMs. ${ }^{a} \mathrm{P}<0.05$ and ${ }^{b} \mathrm{P}<0.01$ vs. OVA-sensitized group. ND, Not detectable.

increases in the levels of serum total $\operatorname{IgE}$ and $\operatorname{IgG} 1$ in the OVA-sensitized group (Table II). Serum total IgE and IgG1 levels were about 6.6 and 2.8 -fold greater, respectively, in the OVA-sensitized group than in the normal control group. Notably, serum levels of total IgE were significantly lower in the TDF 100 and $200 \mathrm{mg} / \mathrm{kg}$ groups than in the OVA-sensitized group, whereas total IgG1 levels were similar.

To add, we obtained similar result after examination of OVA-specific IgE and IgG1 (Table III). OVA-specific IgE and IgG1 levels were obvious in the OVA-sensitized group but barely detectable in the normal control group. TDF treatment concentration-dependently suppressed serum OVA-specific IgE levels, but serum OVA-specific IgG1 levels remained unchanged in the TDF treated group.

Effect of TDF on Th2-related cytokine level in splenocytes isolated from OVA-sensitized mice. By cellular interaction 

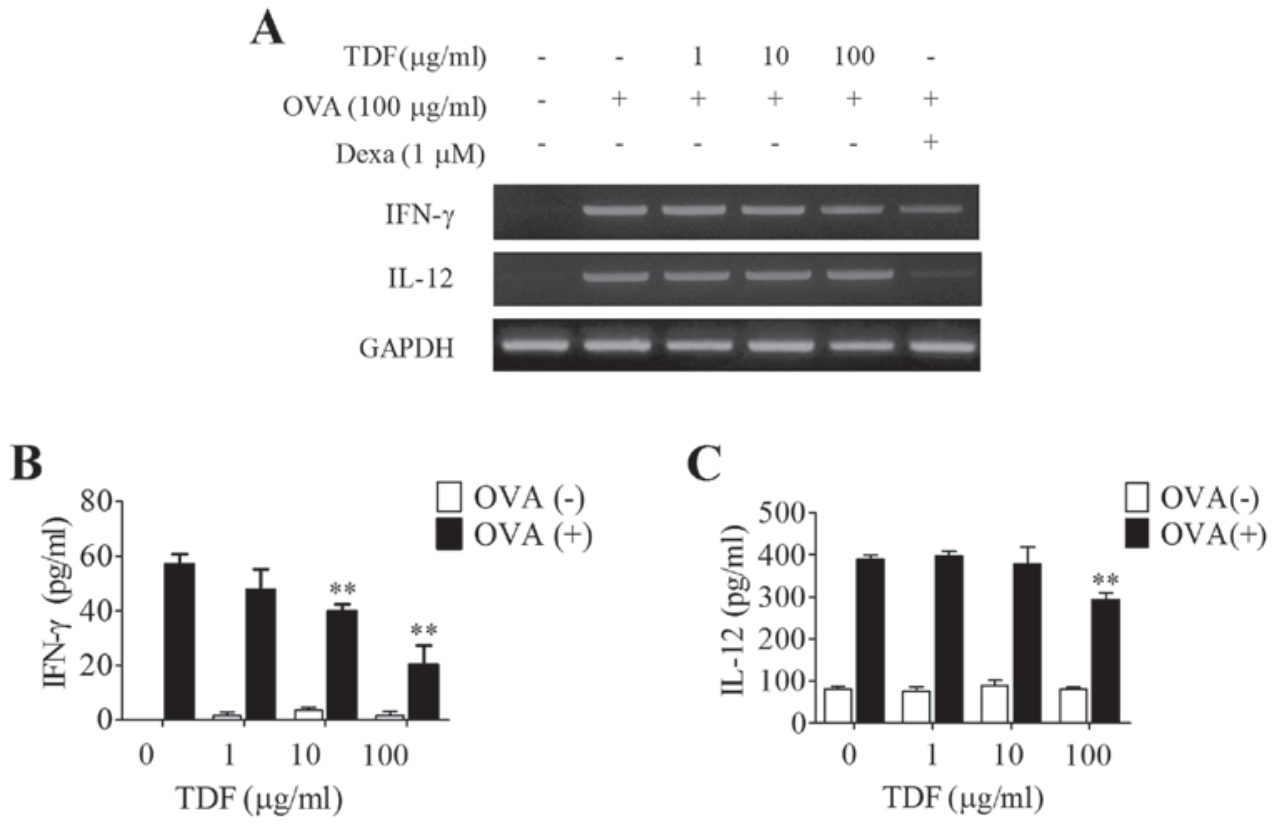

Figure 3. The effect of TDF on Th1 cytokine production in splenocyte culture. The impact of TDF on the Th1 subset was analyzed in splenocytes isolated from OVA-sensitized mice. Splenocytes were incubated with the indicated concentrations of TDF $(1,10,100 \mu \mathrm{g} / \mathrm{ml}) \mathrm{in}$ the absence and presence of $100 \mu \mathrm{g} / \mathrm{ml}$ OVA. (A) The mRNA expressions of Th1 response genes (IFN- $\gamma$, IL-12) were assayed by RT-PCR. GAPDH was used as an internal control. Secretions of Th1 response genes (B) IFN- $\gamma$ and (C) IL-12 in cell supernatant were measured by ELISA. Results are presented as the means \pm SEMs of indipendent three experiments. ${ }^{* *} \mathrm{P}<0.01$ vs. control.

and cytokine secretion, Th cells play a key role in the class switching of B cells. Of the functional Th subsets, Th2 cells are important for enhancing allergic immune response. To determine the effect of TDF on Th2 response, we examined the mRNA and protein levels of Th2-related genes in splenocytes obtained from OVA-sensitized mice.

We observed increases of IL-4, IL-5 and IL-13 mRNA and protein levels in OVA-treated cells. However, TDF treatment at $100 \mu \mathrm{g} / \mathrm{ml}$ attenuated IL-4 mRNA expression and decreased IL-4 secretion (Fig. 2A and B). IL-5 and IL-13 mRNA (Fig. 2A) and protein levels tended (non-significantly) to be lower in TDF treated cells than in OVA-treated cells (Fig. 2C and D).

Effect of TDF on Th1 cytokine levels in splenocytes isolated from OVA-sensitized mice. Th1 and Th2 cells can inhibit each other by secreting cytokines, and naïve $\mathrm{T}$ cells differentiate into Th1 cells in the presence of IL-12, and Th1-derived cytokines (e.g. IFN- $\gamma$ ) are able to suppress Th2 differentiation (26). To investigate the effect of TDF on Th1 response, we examined Th1 response genes in splenocytes obtained from OVA-sensitized mice. Pre-treating splenocytes with TDF had no effect on the mRNA expressions of IFN- $\gamma$ and IL-12 (Fig. 3A). However, IFN- $\gamma$ and IL-12 secretions were significantly reduced by TDF, suggesting TDF reduced the levels of proteins involved in Th1 response without significantly changing mRNA levels (Fig. 3B and C).

Effect of TDF on the expressions of Th specific transcription factors in splenocytes isolated from OVA-sensitized mice. Due to the observed inhibition of Th1/Th2 related cytokine production by TDF in splenocyte culture, we further examined the expressions of transcription factors involved in skewing $\mathrm{T}$ cell polarization toward Th1 and Th2 cells (Fig. 4). As shown in Fig. 4A, TDF markedly inhibited the mRNA expression of T-bet, which plays a key role in Th1 differentiation. Likewise, the mRNA expression of the Th2 specific transcription factor GATA-3 was also inhibited dose-dependently by TDF (Fig. 4B).

\section{Discussion}

The prevalence of allergic diseases has increased in association with the western lifestyle in recent decades. Furthermore, it has been reported more than $25 \%$ of the populations of industrialized countries are under the influence of allergic diseases. The clinical manifestations of allergic diseases such as allergic rhinitis, asthma, atopic dermatitis, food allergy, allergic conjunctivitis and anaphylaxis can occur alone or in combination (27-29). OVA-sensitized animal models are commonly used to mimic chronic allergic diseases such as asthma and atopic dermatitis in human $(30,31)$. In the present study, we investigated the potential ameliorative role of TDF in allergic immune response using OVA-sensitized mouse model.

IgE mediated-mast cell degranulation induces an immediate hypersensitivity reaction to causes allergic inflammation. For example, edema is caused by the movement of immune cells on inflamed site, the expansion of blood vessels, and increased vascular permeability (32). In the present study, allergic cutaneous reaction was suppressed in TDF treated groups as compared with to the OVA-sensitized group. And this effect was comparable to that induced by dexamethasone (the positive control).

Allergic reactions are initiated by enhanced $\mathrm{IgE}$ production induced by activation of the Th2 pathway. Especially, antigen-specific IgE have a key role on mast cells. Mast cells which have FceRI-bound IgE produce a diverse array 
A

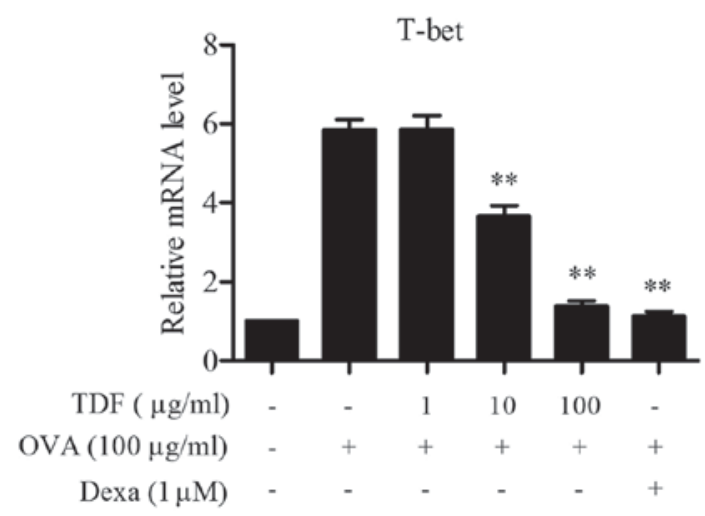

B

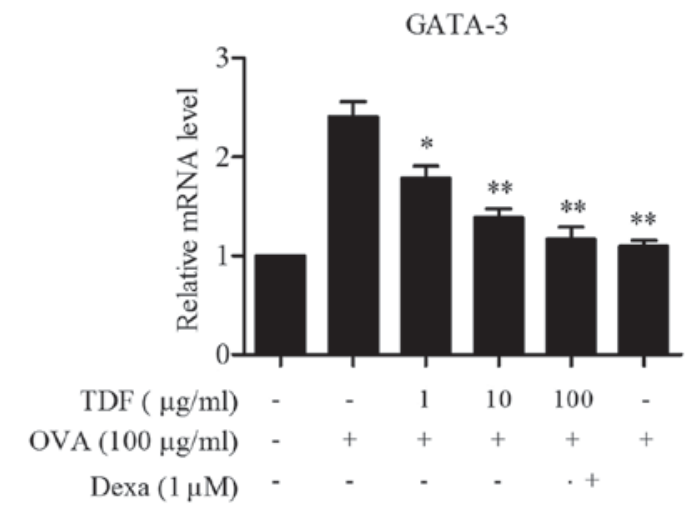

Figure 4. The effect of TDF on the expression levels of Th1/Th2 specific transcription factors in splenocytes. The mRNA expressions of the Th1 specific transcription factor (A) T-bet and Th2 specific transcription factor (B) GATA-3 were assayed by qRT-PCR. Results are presented as the means \pm SEMs of independent three experiments. ${ }^{*} \mathrm{P}<0.05$ and ${ }^{* *} \mathrm{P}<0.01$ vs. control.

of biologically active mediators when re-exposed to the antigens (33). We observed that TDF treatment significantly inhibited the total and OVA-specific IgE, when compared to the OVA-sensitized group. Our in vivo results suggest the observed suppression of allergic inflammation by TDF was due to $\operatorname{IgE}$ down-regulation.

We also investigated $\mathrm{T}$ cell regulation by TDF to explore further the natures of these IgE reductions. After an antigen encountered and bound by antigen presenting cells (APCs) in the body presents, the antigen to naive $\mathrm{CD}^{+} \mathrm{T}$ cells, which then differentiate into functionally distinct subsets as determined by the micro-environmental background.

Th2-biased immune responses commonly results in atopy, and is observed in blood and lung in the presence of asthmatic conditions, and thus, medications targeting Th cells are viewed as promising therapeutic strategies for the treatment of allergic diseases (34). Differentiation of naïve Th precursor cells into Th 2 cells is characterized by the productions of Th 2 cytokines (e.g. IL-4, IL-5 and IL-13). During Th2-development, Th2 signaling initiates activation of signal transducer and activator of transcription (STAT)-6 in the presence of IL-4, which is followed by the expressional up-regulation of GATA-3 (35). We observed TDF decreased the production of IL-4 and the mRNA expression of transcription factor GATA-3 induced by OVA stimulation in splenocyte, which result shows that TDF suppressed Th2 differentiation by inhibiting IL-4 production.

On the other hand, during the development of Th1 lineage cells, antigen stimulates APCs to secret Th1-promoting cytokines such as IL-12 and IFN- $\gamma$. In naïve Th precursor cells during $\mathrm{T}$ cell antigen receptor (TCR) engagement, IFN- $\gamma$ activates STAT-1 and then downstream T-bet expressed in $\mathrm{T}$ cells. Furthermore, T-bet is known as a specific regulator for Th1 differentiation and to be related to IFN- $\gamma$ production (36). Our results show that TDF inhibited the productions of the Th1 cytokines IFN- $\gamma$ and IL-12 and decreased T-bet expression. Although Th1 and Th2 responses can block each other, this result confirmed that TDF does not participate in the induction of Th1 response and suggested that there are other mechanisms for inhibition of Th2 response. In addition, we examined the effect of TDF on other cell subsets such as regulatory $\mathrm{T}$ cells which have protective roles in the presence of excessive immune response. However, TDF was not found to have a significant effect on this subset (data not shown).

Triticum aestivum sprouts are known as contain flavonoids such as isoorientin, isoscoparin and luteolin as well as sterols and polyunsaturated fatty acids $(37,38)$. These constituents have been reported to have the potential to ameliorate allergic diseases. For example, isoorientin was reported to suppress the release of histamine and leukotrienes in guinea pig lung mast cells activated by OVA (39), and luteolin was found to inhibit mast cell-mediated allergic inflammation and to attenuate immediate and late-phase asthmatic responses $(40,41)$. Consistent to these studies, these factors could be evidences for beneficial effect of Triticum aestivum sprouts on allergic diseases.

In conclusion, our data reveal that TDF reduces OVA-induced allergic immune response by inhibiting Th2 differentiation mediated by the activation of GATA-3 and IL-4, and suggest that TDF could be useful for the treatment of allergic diseases. Further studies are required to elucidate the molecular targets associated with the TDF mediated inhibition of allergic immune response.

\section{Acknowledgements}

The present study was financially supported by grants from Wonkwang University (2017).

\section{References}

1. Amin K: The role of mast cells in allergic inflammation. Respir Med 106: 9-14, 2012.

2. Larché M, Akdis CA and Valenta R: Immunological mechanisms of allergen-specific immunotherapy. Nat Rev immunol 6: 761-771, 2006.

3. Bosnjak B, Stelzmueller B, Erb KJ and Epstein MM: Treatment of allergic asthma: Modulation of Th2 cells and their responses. Respir Res 12: 114, 2011.

4. Romagnani S: The role of lymphocytes in allergic disease. J Allergy Clin Immunol 105: 399-408, 2000.

5. Simons FE: Advances in H1-antihistamines. N Engl J Med 351: 2203-2217, 2004

6. Buchman AL: Side effects of corticosteroid therapy. J Clin Gastroenterol 33: 289-294, 2001. 
7. Warrington TP and Bostwick JM: Psychiatric adverse effects of corticosteroids. Mayo Clin Proc 81: 1361-1367, 2006.

8. Petry JJ and Hadley SK: Medicinal herbs: Answers and advice, part 1. Hosp Pract (1995) 36: 57-60, 2001.

9. Balandrin MF, Klocke JA, Wurtele ES and Bollinger WH: Natural plant chemicals: Sources of industrial and medicinal materials. Science 228: 1154-1160, 1985.

10. Mujoriya R and Bodla RB: A study on wheat grass and its Nutritional value. Food Sci Qual Manag 2: 2224-6088, 2011.

11. Wardlaw AJ, Brightling C, Greesn R, Woltmann G and Pavord I Eosinophils in asthma and other allergic diseases. Br Med Bull 56: 985-1003, 2000.

12. Till S, Dickason R, Huston D, Humbert M, Robinson D, Larché M, Durham S, Kay AB, and Corrigan C: IL-5 secretion by allergen-stimulated $\mathrm{CD}^{+} \mathrm{T}$ cells in primary culture: Relationship to expression of allergic disease. J Allergy Clin Immunol 99: 563-569, 1997.

13. Desai TR, Solanki JK, Pankaj Buch and Goyal RK: Triticum aestivum (Wheatgrass): An alternate treatment for the patients with Thalassemia. Orient Pharm Exp Med 7: 466-476, 2008.

14. Luyen BT, Thao NP, Tai BH, Lim JY, Ki HH, Kim DK, Lee YM and Kim YH: Chemical constituents of Triticum aestivum and their effects on adipogenic differentiation of 3T3-L1 preadipocytes. Arch Pharm Res 38: 1011-1018, 2015.

15. Han NR, Kim HM and Jeong HJ: The potential anti-proliferative effect of $\beta$-sitosterol on human mast cell line-1 cells. Can J Physiol Pharmacol 93: 979-983, 2015.

16. Mahajan SG and Mehta AA: Suppression of ovalbumin-induced Th2-driven airway inflammation by $\beta$-sitosterol in a guinea pig model of asthma. Eur J Pharmacol 650: 458-464, 2011.

17. Arm JP, Boyce JA, Wang L, Chhay H, Zahid M, Patil V, Govindarajulu U, Ivester P, Weaver KL, Sergeant S, et al: Impact of botanical oils on polyunsaturated fatty acid metabolism and leukotriene generation in mild asthmatics. Lipids Health Dis 12 141,2013

18. Barros R, Moreira A, Fonseca J, Delgado L, Castel-Branco MG, Haahtela T, Lopes C and Moreira P: Dietary intake of $\alpha$-linolenic acid and low ratio of n-6:n-3 PUFA are associated with decreased exhaled NO and improved asthma control. Br J Nutr 106: 441-450, 2011

19. Park EJ, Kim B, Eo H, Park K, Kim Y, Lee HJ, Son M, Chang YS Cho SH, Kim S and Jin M: Control of IgE and selective TH1 and TH2 cytokines by PG102 isolated from Actinidia arguta. J Clin Immunol 116: 1151-1157, 2005.

20. Schouten B, van Esch BC, Hofman GA, van den Elsen LW, Willemsen LE and Garssen J: Acute allergic skin reactions and intestinal contractility changes in mice orally sensitized against casein or whey. Int Arch Allergy Immunol 147: 125-134, 2008.

21. Hogenkamp A, Thijssen S, van Vlies N and Garssen J: Supplementing pregnant mice with a specific mixture of nondigestible oligosaccharides reduces symptoms of allergic asthma in male offspring. J Nutr 145: 640-646, 2015.

22. Poudel B, Yoon DS, Lee JH, Lee YM and Kim DK: Collagen I enhances functional activities of human monocyte-derived dendritic cells via discoidin domain receptor 2. Cell Immunol 278: 95-102, 2012.

23. Poudel B, Nepali S, Xin M, Ki HH, Kim YH, Kim DK and Lee YM: Flavonoids from Triticum aestivum inhibit adipogenesis in 3T3-L1 cells by upregulating the insig pathway. Mol Med Rep 12: 3139-3145, 2015.
24. Galli SJ, Tsai M and Piliponsky AM: The development of allergic inflammation. Nature 454: 445-454, 2008.

25. Aversa G, Punnonen J, Cocks BG, de Waal Malefyt R, Vega F Jr, Zurawski SM, Zurawski G and de Vries JE: An interleukin 4 (IL-4) mutant protein inhibit both IL-4 or IL-13-induced human immunoglobulin G4 (IgG4) and IgE synthesis and B cell proliferation: Support for a common component shared by IL-4 and IL-13 receptors. J Exp Med 178: 2213-2218, 1993.

26. Kidd P: Th1/Th2 balance: The hypothesis, its limitations and implications for health and disease. Altern Med Rev 8: 223-246, 2003.

27. Akdis CA: Allergy and hypersensitivity Mechanisms of allergic disease. Curr Opin Immunol 18: 718-726, 2006.

28. Yazdanbakhsh M, Kremsner PG and van Ree R: Allergy, parasites, and the hygiene hypothesis. Science 296: 490-494, 2002.

29. Holgate ST and Polosa R: Treatment strategies for allergy and asthma. Nat Rev Immunol 8: 218-230, 2008.

30. Nials AT and Uddin S: Mouse models of allergic asthma: Acute and chronic allergen challenge. Dis Models Mech 1: 213-220, 2008.

31. Jin H, He R, Oyoshi M and Geha RS: Animal models of atopic dermatitis. J Invest Dermatol 129: 31-40, 2009.

32. Zgraggen S, Ochsenbein AM and Detmar M: An important role of blood and lymphatic vessels in inflammation and allergy. J Allergy (Cairo) 2013: 672381, 2013.

33. Galli SJ and Tsai M: IgE and mast cells in allergic disease. Nat Med 18: 693-704, 2012.

34. Heijink IH and Van Oosterhout AJ: Strategies for targeting T-cells in allergic diseases and asthma. Pharmacol Ther 112: 489-500, 2006.

35. Chatila TA, Li N, Garcia-Lloret M, Kim HJ and Nel AE: T-cell effector pathways in allergic diseases: Aanscriptional mechanisms and therapeutic targets. J Allergy Clin Immunol 121: 812-823, 2008

36. Szabo SJ, Kim ST, Costa GL, Zhang X, Fathman CG and Glimcher LH: A novel transcription factor, T-bet, directs Th1 lineage commitment. Cell 100: 655-669, 2000.

37. Lee SH, Xin M, Luyen BT, Cha JY, Im JY, Kwon SU, Lim SW, Suh JW, Kim YH, Kim DK and Lee YM: Inhibitory effect of Triticum aestivum ethanol extract on lipid accumulation in 3T3-L1 preadipocytes. Yakhak Hoeji 55: 478-484, 2011.

38. Luyen BT, Tai BH, Thao NP, Cha JY, Lee YM and Kim YH: A new phenolic component from Triticum aestivum sprouts and its effects on LPS-stimulated production of nitric oxide and TNF- $\alpha$ in RAW 264.7 cells. Phytother Res 28: 1064-1070, 2014

39. Kim DS, Son EJ, Kim M, Heo YM, Nam JB, Ro JY and Woo SS: Antiallergic herbal composition from Scutellaria baicalensis and Phyllostachys edulis. Planta Med 76: 678-682, 2010.

40. Kritas SK, Saggini A, Varvara G, Murmura G, Caraffa A, Antinolfi P, Toniato E, Pantalone A, Neri G, Frydas S, et al: Luteolin inhibits mast cell-mediated allergic inflammation. J Biol Regul Homeost Agents 27: 955-959, 2013.

41. Lee JY, Kim JM and Kim CJ: Flavones derived from nature attenuate the immediate and late-phase asthmatic responses to aerosolized-ovalbumin exposure in conscious guinea pigs. Inflamm Res 63: 53-60, 2014. 